\title{
Assessment of Maternal Near Miss at Debre Markos Referral Hospital, Northwest Ethiopia: Five Years Experience
}

\author{
Molla Gedefaw ${ }^{1 *}$, Habtamu Gebrehana ${ }^{2 \#}$, Ayu Gizachew ${ }^{3}$, Fentahun Taddess ${ }^{4}$ \\ ${ }^{1}$ GAMBY College of Medical Sciences, Bahir Dar, Ethiopia \\ ${ }^{2}$ Debre Markos Referral Hospital, Ethiopia \\ ${ }^{3}$ Department of Reproductive Health, Debre Markos University, Debre Markos, Ethiopia \\ ${ }^{4}$ Debre Markos Town Administration, Ethiopia \\ Email: *mollagedefaw@yahoo.com, hgebrehana@yahoo.com, ayugizachew@yahoo.com, \\ fentadese760@yahoo.com
}

Received 9 August 2014; revised 9 September 2014; accepted 9 October 2014

Copyright (C) 2014 by authors and Scientific Research Publishing Inc.

This work is licensed under the Creative Commons Attribution International License (CC BY). http://creativecommons.org/licenses/by/4.0/

c) (i) Open Access

\begin{abstract}
Maternal mortality in Ethiopia is one of the highest in the world. Data on maternal near miss cases and events among mothers who received care at health institutions is lacking. The main aim of this study was, therefore, to assess trend and correlates of maternal near miss case at a referral hospital. Case notes of clients who received care in obstetric and gynecologic ward of Debre Markos Referral Hospital from $1^{\text {st }}$ January 2008 to $30^{\text {th }}$ December 2012 were reviewed. Case notes were selected using systematic random sampling technique. Tailored format was data collection tool. SPSS version 16 was used to analyze the data. Logistic regression was fitted to determine possible association, and strength of associations was measured using odds ratio at $95 \%$ confidence interval. A total of 1355 case notes were reviewed. Of them, 403 (29.7\%) were near miss cases. The data showed that maternal near miss ratio over the study period was decreasing $\left(X^{2}=7.4, p=0.007\right)$. Distance from the hospital, history of difficult labor, and antenatal care (ANC) utilization were found to be major determinates of maternal near miss cases. The most common types of near miss events were obstructed labor and hemorrhage. Majority of maternal near miss cases brought referral letter to hospital. Although maternal near miss ratio is still high, it appears to decrease over the last five years period. This may reflect success of the government's Endeavour to decrease maternal mortality. However, this effort needs to continue in a sustainable manner to avoid preventable causes of maternal mortality in Ethiopia.
\end{abstract}

\footnotetext{
*Corresponding author.

"Formerly, this author had been graduate student in Joint MPH program (Debre Markos University and GAMBY College of Medical Sciences), Debre Markos, Ethiopia.

How to cite this paper: Gedefaw, M., Gebrehana, H., Gizachew, A. and Taddess, F. (2014) Assessment of Maternal Near Miss at Debre Markos Referral Hospital, Northwest Ethiopia: Five Years Experience. Open Journal of Epidemiology, 4, 199207. http://dx.doi.org/10.4236/ojepi.2014.44026
} 


\section{Keywords}

\section{Maternal Near Miss, Maternal Near Miss Events, Maternal Death}

\section{Introduction}

Maternal near miss is said to be occurred when women presented with life threatening complication during pregnancy, child birth and within 42 days after delivery, but survive by chance or good institutional care. Currently maternal near-miss ratio is increasingly used to evaluate the quality of obstetric care in low income countries [1].

Literatures indicate that maternal mortality has decreased worldwide. However, maternal mortality remains high in low income countries in which $99 \%$ of the deaths occur. Of this, Sub-Saharan Africa alone shoulders three fifth of maternal deaths [2].

Risk of maternal mortality is 1 in 30 in Sub-Saharan Africa. This figure is 1 in 5,600 in industrialized countries [3]. In order to device appropriate strategy to curb maternal mortality in these countries, knowing the statistics on levels of maternal mortality and morbidity is not enough. Reliable information on the underlying factors which lead to maternal complication and death is needed [4].

According to Ethiopian demographic and health survey 2011, the maternal mortality ratio was 676/100,000 live births. In Ethiopia 20,000 women die each year from pregnancy complications-during pregnancy, child birth and post partum period [5].

Well aware of these facts, the government of the federal democratic republic of Ethiopia attempts to reduce maternal mortality using different strategies [6]. Training human resource for health, construction health institutions, procuring vehicles for transporting mothers to health institutions, and making reproductive health services free or minimal charge are some of the interventions the government in collaboration with development partners is doing.

Currently, Amhara National Regional State alone constructs more than thirty hospitals. It had only twelve hospitals rendering health care for about 20 million people. However, data on trend of maternal near miss ratio, and maternal near miss events are lacking. The present study tried to fill the prevailing knowledge gap. The finding of the study could be used by different stakeholders including hospital management, regional health bureau, and development partners to further improve the care to women, and finally reduce maternal mortality.

\section{Methods and Materials}

Case notes of mothers who received care at department of gynecology and obstetrics of Debre Markos Referral Hospital over five years period was reviewed. Debre Markos is located $300 \mathrm{~km}$ far from the capital city of Ethiopia, Addis Ababa, and 256 km from Bahirdar a capital city of Amhara National Regional State. The Hospital provides health service to more than 3.5 million populations. Currently about 100 health centers and two district hospitals are available in the catchment area of the referral hospital.

Currently there are 109 Nurse, three health officer, 16 General practitioners, one emergency surgeon and five specialists. Gynecologic and obstetric ward has 19 midwifes, one gynecologist and one emergency surgeon. About 8136 patients are admitted per year, 34\% of them in obstetric ward.

The study was conducted using available data form $1^{\text {st }}$ January 2008 to $30^{\text {th }}$ December 2012. Data was collected from July to August, 2013. The case notes were randomly selected from a list of all women who were admitted in obstetrics and Gynecology ward for any pregnancy related health service from $1^{\text {st }}$ January 2008 to $30^{\text {th }}$ December 2012. The cases notes were selected using systematic random sampling.

The sample size was determined by using single population proportion formula. Considering 95\% confidence interval and 2\% margin of error and proportion of critically ill obstetric patients among total delivery 17\% [7], the total sample size was 1355. Patient's case note list was obtained from registered log book and then case notes were selected from each year proportionally. Incomplete notes in which important variables were not recorded were excluded. Data were collected from the selected case notes using tailored structured formats developed for the study.

WHO maternal near miss diseases specific criteria (obstructed labor, hemorrhage, pregnancy induced hyper- 
tension, septic abortion and sepsis/infection) were used to identify maternal near miss cases from randomly selected case notes. Data were extracted from the case notes by trained midwife nurses. Questionable case notes were brought to the attention of the researchers for decision. Furthermore, each data collection format was reviewed daily by a supervisor or principal investigator to check for completeness and consistency of the collected data.

The collected data were entered in Epi-info version 3.4.3 and were cleaned and exported to SPSS version 16 for windows for analysis. Binary logistic regression model was fitted to assess possible association. Strength of associations, and statistical significance were measured using odds ratio at $95 \%$ confidence interval. The results were presented in the form of tables, and figures.

This study received Ethical clearance from Debre Markos University, post graduate research and institutional review board and permission was obtained Debre Markos Referral Hospital.

\section{Result}

A total of 1355 case notes were reviewed. Of these, 403 (29.7\%) were near miss cases. A total of 409 near miss events were identified among near miss cases, indicating six women had more than one life threatening condition. There were 1,157 deliveries, 185 abortion and 11 ectopic pregnancies.

Of the deliveries, 1048 (90.6\%) were live births and 109 (9.4\%) were still births. Of the total deliveries, 709 (61\%) had spontaneous vaginal delivery. Cesarean section was done for 177 (13\%) cases. Of these, 152 (86\%) were for near miss cases. Laparatomy was performed for ruptured uterus 28 (2\%) (Figure 1).

About $80 \%$ of near miss cases brought referral paper from governmental and private health institutions. Of the total near miss cases, 362 (90\%) were admitted with near miss events. Further $10 \%$ of near miss-cases develop near miss events after admission. Twenty five per cent of near miss cases were transfused with at least one unit of blood. Blood was transfused for women whose haematocrite was less than $21 \%$. About $50 \%$ of near miss cases stayed in the hospital for more than six days (Table 1 ).

During the 5-years period, the trend of maternal near miss ratio has decreased almost from 50\% to $34 \%$.

The ratio of maternal near miss cases observed to this facility has decreased significantly $(\mathrm{X} 2=7.4, \mathrm{p}=0.007)$ (Figure 2).

The most common types of near-miss events fall under the diagnostic categories of obstructed labor, hemorrhage and pregnancy induced hypertension. Obstructed labor and hemorrhage were responsible for $45 \%$ and $43 \%$ of near-miss cases, respectively. Hemorrhage at early pregnancy, late pregnancy and postpartum period were $17.11 \%, 9.05 \%$ and $16.63 \%$, respectively. Least common cases of life threatening condition were septic abortion and infection, accounts $4 \%$ (Figure 3 ).

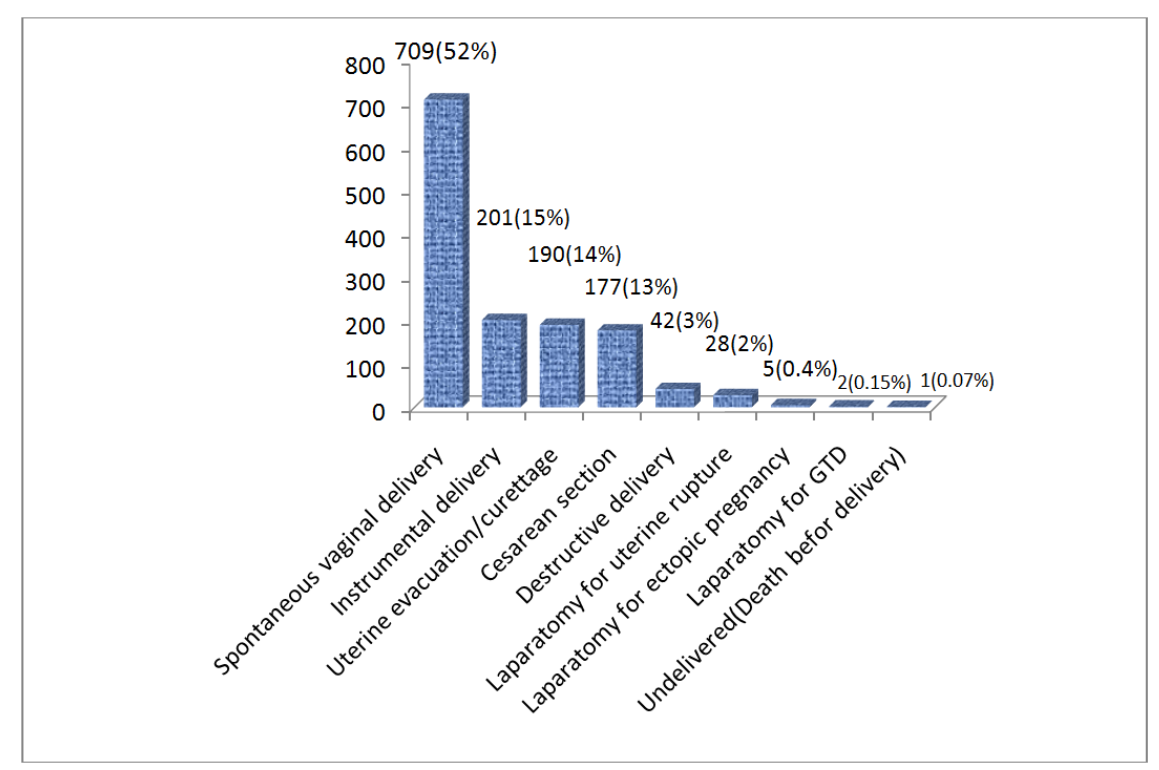

Figure 1. Modes of delivery in Debre Markos Referral Hospital (2008-2012). 
Table 1. Characteristics of maternal near miss cases in Debre Markos Referral Hospital (2008-2012).

\begin{tabular}{|c|c|c|c|}
\hline Near miss case characteristics $(n=403)$ & & Frequency & Percentage \\
\hline \multicolumn{4}{|l|}{ Referral linkage } \\
\hline Self referral & & 71 & 18 \\
\hline Referred from health institution & & 332 & 82 \\
\hline \multicolumn{4}{|l|}{ Occurrence of near miss events } \\
\hline Before admission & & 362 & 90 \\
\hline During Hospitalization & & 41 & 10 \\
\hline \multicolumn{4}{|l|}{ Status at admission } \\
\hline Stable & & 208 & 52 \\
\hline Un stable & & 195 & 48 \\
\hline \multicolumn{4}{|l|}{ HCT Level } \\
\hline$>33 \%$ & & 238 & 59 \\
\hline $21 \%-33 \%$ & & 102 & 25 \\
\hline$<21 \%$ & & 63 & 16 \\
\hline \multirow[t]{2}{*}{ Transfused at least one unit of blood } & YES & 102 & 25 \\
\hline & NO & 301 & $75 \%$ \\
\hline \multicolumn{4}{|l|}{ Duration of Hospital stay in hours } \\
\hline$<=48$ & & 94 & 23.33 \\
\hline $49-96$ & & 46 & 11.40 \\
\hline $97-144$ & & 55 & 13.65 \\
\hline $145-196$ & & 174 & 43.18 \\
\hline$>=197$ & & 34 & 8.44 \\
\hline
\end{tabular}

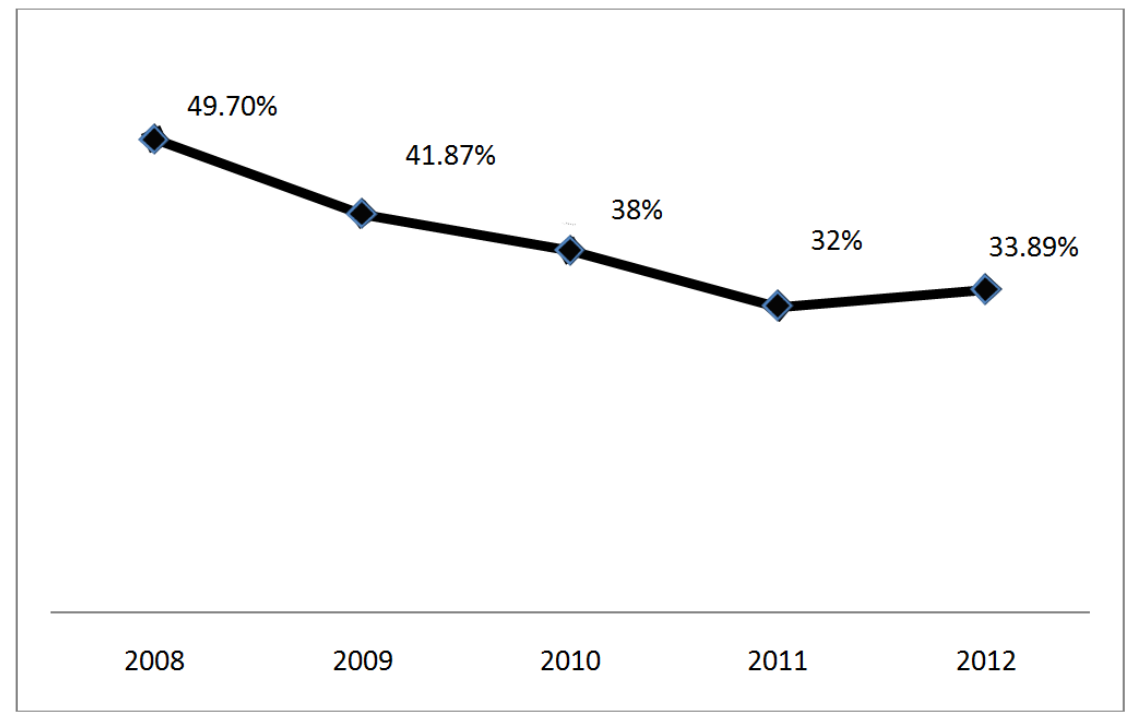

Figure 2. Trends of maternal near miss ratio over five years period, 2008-2012 in Debre Markos Referral Hospital. 


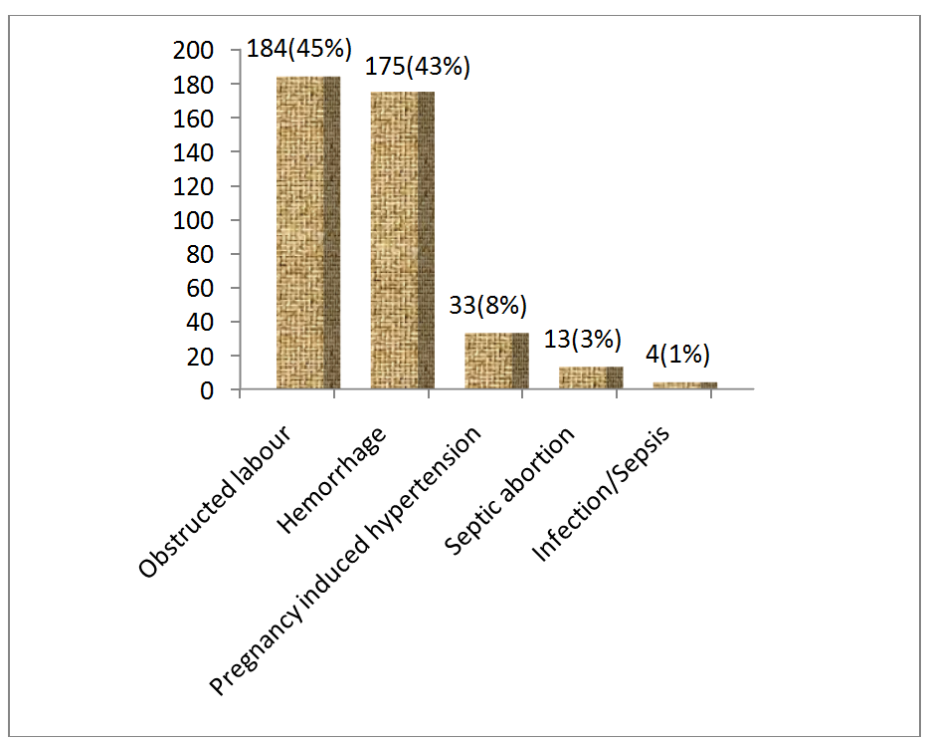

Figure 3. Most common cause of life threatening condition from 20082012 in Debre Markos Referral Hospital.

Multiple logistic regressions revealed that distance between residences of the clients and this referral hospital had significant association with maternal near miss case. For instance, those who resided $25 \mathrm{~km}$ and far from the hospital were two times more likely to suffer from near miss events than those who came from less than $25 \mathrm{~km}$ $(\mathrm{OR}=1.9,95 \% \mathrm{CI}=1.17-2.94)$.

Birth weights, bad obstetric history, parity, gravidity, ANC follow up were found to have statistically significant association with the occurrence of maternal near miss events. For instance, those mothers who gave birth to neonate with a birth weight of $4 \mathrm{~kg}$ and more were three times more likely to develope life threatening condition than their counter parts. $(\mathrm{OR}=3.3,95 \% \mathrm{CI}=1.9-5.7)$. Similarly, mothers who had at least one bad obstetric history were two times more likely to face near miss event(s) than their counter parts (OR $=1.99,95 \%=1.1$ 3.3) (Table 2).

\section{Discussion}

The study showed that total maternal near-miss ratio were 384.5/1000 live births. The ratio of maternal near miss was very high (38\%) as compared to studies done in other African countries [8]-[10]. The difference could be explained by different health delivery strategies, differences in socio-demographic characteristics of the populations and differences in case definitions [11]-[14]. In the present study, maternal near miss was defined according to the WHO disease specific criteria.

The frequency of maternal near miss events showed a decreasing trend over the study period (2008-2012). This reduction is statistically significant $\left(X^{2}=7.4, p=0.007\right)$. This is in agreement with a study done in Nigeria from 2002-2004 [7]. However, the magnitude of maternal near miss ratio still remains high.

The most common near miss events in the present study were obstructed labor and hemorrhage, and the least cause of maternal near miss events were septic abortion and sepsis. This finding is in line with Ethiopian demographic health survey (EDHS) 2011. Studies in other African countries indicated that common cause of maternal near miss events were hemorrhage and infection (9), hemorrhage and hypertension [7] [12] [15]. This shows that hemorrhage is an important maternal near miss event across Africa.

In the present study, duration of hospital stay for near miss cases ranged from 1 - 18 days. This finding is comparable to the findings in Kassala Hospital (in Sudan). In Kassala it ranged 3 - 15 days [9]. The present study also revealed that more than half of near miss cases (52\%) stayed for more than six days in the hospital.

Our hospital has no intensive care unit (ICU). All gynecology and obstetrics cases were treated in the same ward. Studies in Nigeria [7], Damascus [15] and Bangladesh [16] revealed that hospitals do have intensive care unit dedicated to mothers admitted to obstetric ward. 
Table 2. Socio-demographic and obstetric determinants of near miss cases in Debre Markos Referral Hospital from 20082012.

\begin{tabular}{|c|c|c|c|c|}
\hline Variables $(n=1351)$ & Near miss & Non near miss & Crude OR (95\% CI) & Adjusted OR (95\% CI) \\
\hline \multicolumn{5}{|l|}{ Age } \\
\hline$<20$ & 41 & 74 & $1.6(1.1-2.4)$ & $1.9(0.95-3.9)$ \\
\hline $20-34$ & 268 & 773 & 1.00 & 1.00 \\
\hline$>=35$ & 94 & 101 & $2.7(1.96-3.67)$ & $1.3(0.7-2.6)$ \\
\hline \multicolumn{5}{|l|}{ Resident } \\
\hline urban & 100 & 535 & 1.00 & 1.00 \\
\hline rural & 303 & 413 & $3.9(3.03-5.09)$ & $2.1(1.4-3.1)$ \\
\hline \multicolumn{5}{|l|}{ Distance in Km } \\
\hline$<=24$ & 84 & 420 & 1.00 & 1.00 \\
\hline $25-74$ & 218 & 389 & $2.8(2.1-3.7)$ & $1.9(1.2-2.9)$ \\
\hline $75-99$ & 67 & 98 & $3.42(2.3-5.0)$ & $2.7(1.5-4.8)$ \\
\hline$>=100$ & 34 & 41 & $4.2(2.5-6.9)$ & $2.5(1.2-5.3)$ \\
\hline \multicolumn{5}{|l|}{ ANC } \\
\hline Yes & 176 & 686 & 1.00 & 1.00 \\
\hline No & 227 & 262 & $3.4(2.65-4.31)$ & $1.9(1.3-2.8)$ \\
\hline \multicolumn{5}{|l|}{ Parity $(n=1351)$} \\
\hline 0 & 171 & 384 & $1.6(1.2-2.1)$ & $2.9(1.1-8.2)$ \\
\hline 1 & 73 & 220 & $1.1(0.8-1.6)$ & $2.3(1.2-4.2)$ \\
\hline $2-4$ & 82 & 306 & 1.00 & 1.00 \\
\hline$>=5$ & 77 & 38 & $6(3.8-9.5)$ & $2.6(1.1-6.1)$ \\
\hline \multicolumn{5}{|l|}{ Gravida (n =1351) } \\
\hline 1 & 172 & 377 & $1.8(1.4-2.3)$ & $1.2(1.02-7.4)$ \\
\hline $2-4$ & 127 & 488 & 1.00 & 1.00 \\
\hline$>=5$ & 104 & 83 & $4.8(3.4-6.8)$ & $2.9(1.3-6.3)$ \\
\hline \multicolumn{5}{|l|}{ GA $(n=1074)$} \\
\hline$<=28$ & 79 & 116 & $2.0(1.44-2.80)$ & $2.1(0.29-15.04)$ \\
\hline $28.14-36.86$ & 28 & 110 & $0.75(0.48-1.18)$ & $0.7(0.43-1.26)$ \\
\hline $37-42$ & 177 & 522 & 1.00 & 1.00 \\
\hline$>42$ & 12 & 30 & $1.18(0.59-2.35)$ & $0.9(0.45-2.12)$ \\
\hline \multicolumn{5}{|l|}{ Birth weight $(n=1094)$} \\
\hline $1-1.499$ & 3 & 6 & $1.9(0.46-7.45)$ & $0.96(0.1-6.5)$ \\
\hline $1.5-2.499$ & 19 & 64 & $1.1(0.64-1.87)$ & $1.01(0.5-2.01)$ \\
\hline $2.5-3.999$ & 194 & 716 & 1.00 & 1.00 \\
\hline$>=4$ & 46 & 46 & $3.7(2.38-5.72)$ & $3.3(1.9-5.7)$ \\
\hline \multicolumn{5}{|c|}{ Bad obstetric history ( $n=1351$ ) } \\
\hline YES & 84 & 74 & $3.11(2.22-4.36)$ & $1.9(1.1-3.3)$ \\
\hline NO & 319 & 874 & 1.00 & 1.00 \\
\hline
\end{tabular}

COR = crude odds ration; $\mathrm{AOR}=$ adjusted odds ratio. 
Of the total near miss cases, $82 \%$ were referred from governmental and private health institutions. This figure is comparable to figures in Syria and Bangladesh. Reports from these two countries indicated that about 93\% of near miss cases were referred in critical condition from different health institutions [15] [16].

In the present study, majority of near miss cases (90\%) were admitted with at least one near miss event while about $10 \%$ of cases became near miss after admission. This finding is in agreement with a study done in Sagamu, Nigeria [7].

In our set up, this situation could be interpreted as good because it shows a functional referral system from low level health care institution to a high level care.

The very existence of the referral system saves the lives of mothers as depicted in this study. However, the study revealed also that nearly 50\% near miss cases were critical ill/unstable at admission, lost much of their blood. This could be partly explained by the fact that mothers reached to the near by health center late because institutional delivery in Ethiopia in general and in Amhara Regional State in particular is still less than 20\%.

The finding of the present study also revealed that maternal near miss events occurred more than two times among rural women compared to their urban counterparts. This finding was in agreement with previous studies conducted in other areas of the country [17]. This might be due to the fact that urban women do have better access to information, and to delivery services. On the other hand, rural women are mostly influenced by traditional practices [5].

Distance between place of residence of clients and this referral hospital was found to be an important predictor for a mother became maternal near miss. This finding is in line with other studies [18] [19]. Correspondingly, the finding is supported by three delays of maternal death specifically delay in reaching health facility [10].

The study also revealed that there is a statistically significant association between ANC visit during last pregnancy and occurrence of maternal near miss events. Women who didn't have ANC visits were two times more likely to become maternal near miss case than mothers who had visit ANC. The result was in line with other studies done [6] [7] [13] [16]. This could be due to the fact that ANC provides mothers with opportunities to get health education and information regarding danger signs of pregnancy, labor and post partum period as well as the benefits of having a skilled birth attendant during childbirth.

Parity and gravidity were also other important predictors for the occurrence of maternal near miss events. Women with higher parity were more likely to develop near miss events than mothers who gave birth for the first time. This finding agrees with several other studies [8] [20]. This might be partly explained by the fact that women who experienced prior peaceful labor at home delivery might believe that things go similarly every time in pregnancy and might decide to give birth at home.

Likewise, the present study revealed that women with prior bad obstetric history were more likely to become maternal near miss case than their counter parts. This is in accordance with similar studies [21]. Though every pregnancy entails risk to mothers, those mothers with known risks could have higher risk than those with no known risk factors.

The major limitation of the present study is that because of lack of standard format about what variables should be documented in every maternal case note book, some relevant variables were not registered in the case note books. Moreover, the study has confined itself in only one referral hospital; hence it has limited scope for a region with about 20 million people.

However, the finding could be almost similar to situations in other referral hospitals in the region. Therefore, the finding of this study is informative about maternal near miss, maternal near miss events, and predictors of maternal near miss in the region, and other areas with similar contexts.

\section{Conclusion}

Although maternal near miss ratio is still high, it appears to decrease over the last five years period. This may reflect success of the government's Endeavour to decrease maternal mortality. However, this effort needs to continue in a sustainable manner to avoid preventable causes of maternal mortality in Ethiopia.

\section{Acknowledgements}

We would like to thank Debre Markos University and GAMBY College of Medical Sciences for opening a joint MPH training program which increases research and training opportunities in our region. We are also very grateful for supervisors and data collectors. 


\section{Conflict of Interest}

We declare that there is no conflict of interest in this research.

\section{Contribution of Authors}

H.G.: raised the research idea, wrote the first proposal, as well as manuscript drafts. M.G., and A.G. reviewed and finalized them. F.T. performed the statistical analysis.

\section{References}

[1] WHO (2011) Evaluating the Quality of Care for Severe Pregnancy Complications: The WHO Near Miss Approach for Maternal Health. World Health Organization

[2] Chou, D., Inoue, M., Mathers, C., Oestergaard, M., Say, L., Mills, S., et al. (2010) Trends in Maternal Mortality: 1990 to 2008. Estimates Developed by WHO, UNICEF, UNFPA and The World Bank.

[3] UN (2010) We Can End Poverty 2015 Millennium Developmental Goal. The Millennium Development Goals Report.

[4] World Health Organization (2004) Beyond the Numbers: Reviewing Maternal Deaths and Complications to Make Pregnancy Safer. Geneva.

[5] Maternal Death Surveillance and Response (MDSR) Technical Guideline (2012) Ministry of Health of Ethiopia Addis Ababa, Ethiopia.

[6] Trends in Maternal Health in Ethiopia (2012) In-Depth Analysis of the EDHS 2000-2011. UNFPA, Addis Ababa, Ethiopia.

[7] Oladapo, O.T., Sule-Odu, A.O., Olatunji, A.O. and Daniel, O.J. (2005) Near-Miss Obstetric Events and Maternal Deaths in Sagamu, Nigeria: A Retrospective Study. Reproductive Health, 2, 9. http://dx.doi.org/10.1186/1742-4755-2-9

[8] Wianwiset, W. (2012) Maternal Near Miss (Severe Morbidity) at Sisaket Hospital. Thai Journal of Obstetrics and Gynecology, 20, 69-76.

[9] Ali, A., Khojali, A., Okud, A., Adam, G.K. and Adam, I. (2011) Maternal Near-Miss in a Rural Hospital in Sudan. BMC Pregnancy and Child Birth, 11, 48. http://dx.doi.org/10.1186/1471-2393-11-48

[10] Amaral, E., Souza, J.P., Surita, F., Campbell, O., Guilherme, J., et al. (2011) A Population-Based Surveillance Study on Severe Acute Maternal Morbidity (Near-Miss) and Adverse Perinata Outcomes in Campinas, Brazil. BMC Pregnancy and Childbirth, 11, 9. http://dx.doi.org/10.1186/1471-2393-11-9

[11] Kaye, D.K., Kakire, O. and Osinde, M.O. (2011) Systematic Review of the Magnitude and Case Fatality Ratio for Severe Maternal Morbidity in Sub-Saharan Africa between 1995 and 2010. BMC Pregnancy and Childbirth, 11, 65. http://dx.doi.org/10.1186/1471-2393-11-65

[12] Drau, P.H., Musa, J., Achara, P. and Pam, I.C. (2008) Near Miss Maternal Mortality in Jos University Teaching Hospital (Juth), Jos, Plateau State Nigeria. Department of Obstetrics and Gynecology, Jos University Teaching Hospital, Jos, Plateau State. Ibom Medical Journal, 3, 1.

[13] Mustafa, R. and Hashmi, H. (2009) Near-Miss Obstetrical Events and Maternal Deaths. Journal of the College of Physicians and Surgeons Pakistan, 19,781-785.

[14] Say, L., Pattinon, R.C. and Gulmezoglu, A.M. (2004) WHO Systematic Review of Maternal Morbidity and Mortality: The Prevalence of Severe Acute Maternal Morbidity (Near Miss). Reproductive Health, 1, 3. http://dx.doi.org/10.1186/1742-4755-1-3

[15] Almerie, Y., Almerie, M.Q., Matar, H.E., Shahrour, Y., Chamat, A.A. and Abdulsalam, A. (2010) Obstetric Near-Miss and Maternal Mortality in Maternity University Hospital, Damascus, Syria: A Retrospective Study. BMC Pregnancy and Childbirth, 10, 65. http://dx.doi.org/10.1186/1471-2393-10-65

[16] Sikeder, S.S., Labrique, A.B., Ullah, B., Ali, H., Rashid, M., Mehra, S., et al. (2011) Accounts of Severe Acute Obstetric Complications in Rural Bangladesh. BMC Pregnancy and Childbirth, 11, 76. http://dx.doi.org/10.1186/1471-2393-11-76

[17] Jabir, M., Abul-Hassan, S., Abdul-Salam, l., AL-Hilli, W., Abul-Hassan, S., et al. (2013) Maternal Near Miss and Quality of Maternal Health Care in Baghdad, Iraq. BMC Pregnancy and Childbirth, 13, 11. http://dx.doi.org/10.1186/1471-2393-13-11

[18] Abdella, A. (2010) Maternal Mortality Trend in Ethiopia. Ethiopian Journal of Health Development, 24, 115-122.

[19] Gaym, A. (2000) A Review of Maternal Mortality at Jimma Hospital, South East Ethiopia. Ethiopian Journal of Health Development, 14, 215-223. 
[20] Kabakyenga, J.K., Ostergren, P.O., Turyakira, E., Mukasa, P.M. and Pettersson, K.O. (2011) Individual and Health Facility Factors and the Risk for Obstructed Labor and Its Adverse Outcomes in South-Western Uganda. BMC Pregnancy and Childbirth, 11, 73. http://dx.doi.org/10.1186/1471-2393-11-73

[21] Imam, A.M., Dhaher, E., et al. (2012) Maternal near Miss in Four Governmental Hospitals in the West Bank, Occupied Palestinian Territory, in 2010: A Retrospective, Facility-Based Survey. The Lancet, 380, S37-S38. 
Scientific Research Publishing (SCIRP) is one of the largest Open Access journal publishers. It is currently publishing more than 200 open access, online, peer-reviewed journals covering a wide range of academic disciplines. SCIRP serves the worldwide academic communities and contributes to the progress and application of science with its publication.

Other selected journals from SCIRP are listed as below. Submit your manuscript to us via either submit@scirp.org or Online Submission Portal.
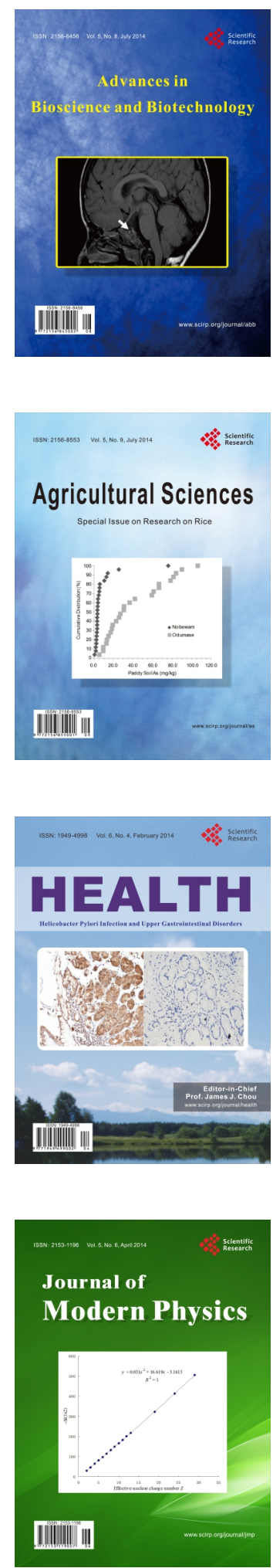
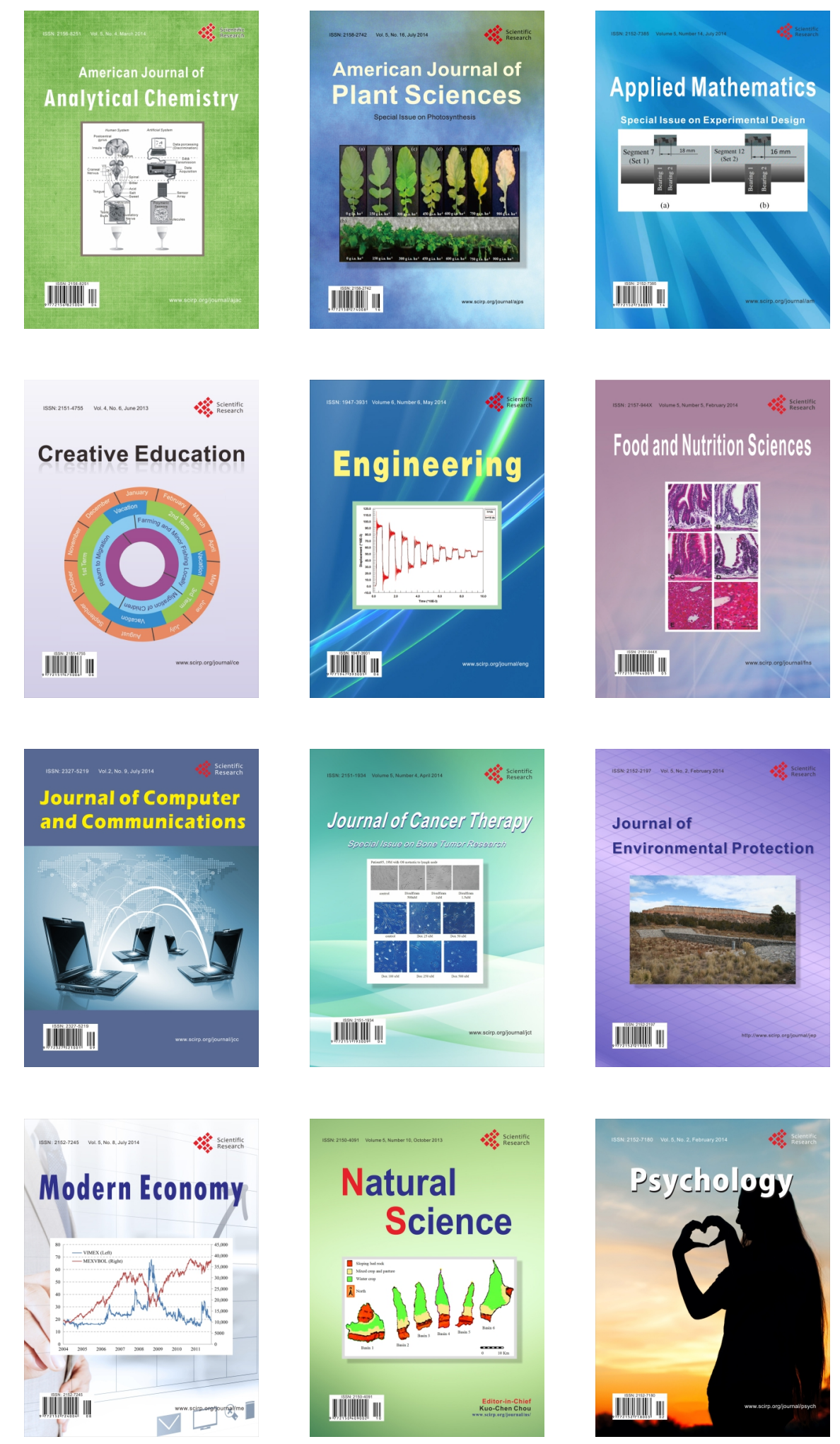